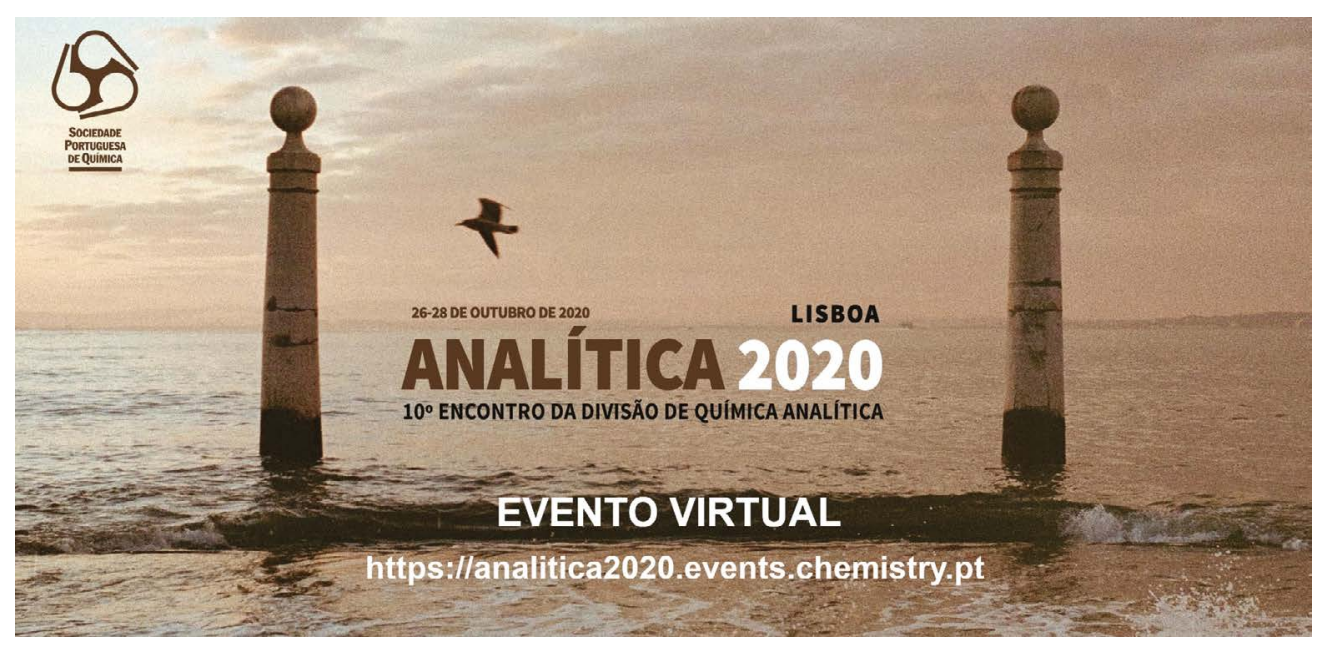

\title{
ANALÍTICA 2020
}

0 10. Encontro da Divisão de Química Analítica da SPQ, ANALÍTICA 2020, decorreu em modo virtual, on-line, de 26 a 28 de outubro. Coordenado na Faculdade de Ciências da Universidade de Lisboa (FCUL), teve início com o curso "Um Dia com pH", evento do projeto europeu UnipHied em que o CQE@FCiências é parceiro. Como nas edições anteriores do ANALÍTICA, foram focados os desenvolvimentos recentes de química analítica e as suas aplicações em áreas que vão desde o ambiente e alimentos, até à saúde e à indústria. Foi também reconhecido o papel que a Química Analítica desempenha para alcançar os objetivos do desenvolvimento sustentável, descritos na Agenda 2030 das Nações Unidas, através de monitorização, por exemplo, da acidificação oceânica, de poluentes vários, de microcontaminantes e de fármacos no ambiente.

No primeiro dia, 26 de outubro, o curso sobre pH, nas suas diferentes vertentes desde conceitos fundamentais de acidimetria e abordagens mais clássicas, até situações emergentes de medição em matrizes complexas como a água dos oceanos e solventes mistos, foi coordenado por Maria Filomena Camões.

O ANALÍTICA 2020 prosseguiu nos dias 27 e 28 de outubro, com duas lições plenárias proferidas por Ivo Leito (Univ. Tartu, Estónia) e Marcela Segundo (Univ. do Porto), cinco lições convidadas, trinta comunicações orais distribuídas em duas sessões paralelas pelos tópicos de novas metodologias, metrologia e validação, métodos de separação, sensores e biossensores, ambiente, alimentos e aplicações biomédicas. Adicionalmente, 34 apresentações em painéis, disponíveis na plataforma virtual do encontro, foram objeto de apresentação oral poster-pitch, o que enriqueceu o conteúdo e promoveu um contacto mais próximo e a discussão entre os participantes presentes em modo virtual. Foram ainda atribuídos prémios para as três melhores comunicações orais a Ana Catarina Rocha (Instituto Hidrográfico, Lisboa), Bárbara Anes (Univ. Lisboa) e Sara Marques (Univ. Porto), e três melhores painéis a Carlos Monteiro (Univ. Lisboa), Margarida Nunes (Univ. Évora) e Priscila Estevão (Univ. Federal do Paraná, Brasil).

Numa altura em que os encontros presenciais não são possíveis, a realização do ANALÍTICA 2020, na modalidade on-line, demonstrou ser eficaz e importante para permitir a continuação dos eventos científicos já planeados, tendo-se revelado um sucesso na promoção e partilha da Química Analítica entre uma comunidade ativa que aderiu e se manifestou de forma entusiasta.

0 próximo ANALÍTICA, 11. ${ }^{\circ}$ Encontro da Divisão de Química Analítica, está previsto para o ano de 2022, nas melhores condições que as circunstâncias permitirem.

Agradecemos à Comissão Organizadora, à Comissão Científica e ao Secretariado da SPQ o seu empenho em tornar este encontro virtual uma realidade.
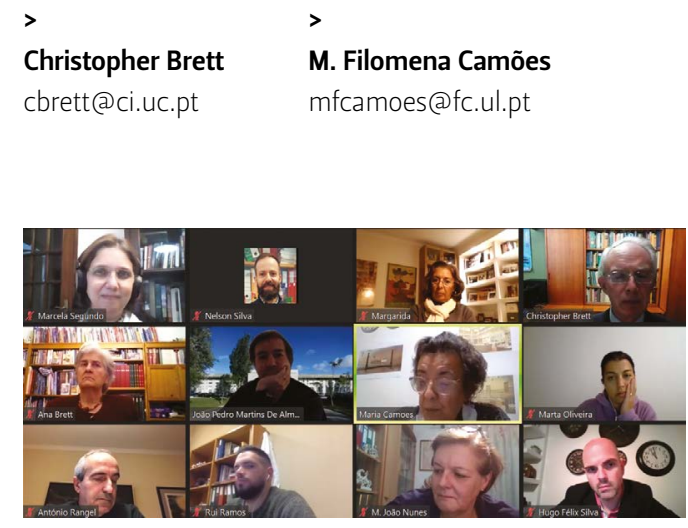

Captura de ecrã tirada durante uma das sessões Zoom 